\title{
BMJ
}

\section{Effects of treatments for symptoms of painful diabetic neuropathy: systematic review}

\author{
Man-chun Wong, pain management nurse, , Joanne W Y Chung, professor, ${ }^{2}$ Thomas K S Wong, \\ chair professor ${ }^{2}$
}

${ }^{1}$ Nursing Services Division,

United Christian Hospital,

130 Hip Wo Street, Hong Kong

${ }^{2}$ School of Nursing, Hong Kong Polytechnic University, Hong Kong Correspondence to: M C Wong wongmc0829@yahoo.com.hk

doi:10.1136/bmj.39213.565972.AE

This is version 2 of the paper. Version 1 incorrectly stated that the pooled odds ratio for withdrawal related to adverse events with traditional [rather than newer generation] anticonvulsants was 2.98 .

\section{ABSTRACT}

Objective To evaluate the effects of treatments for the symptoms of painful diabetic neuropathy.

Design Systematic review.

Data sources Articles (English and full text) on double blind randomised trials found by searching with the key words anticonvulsant, antidepressant, non-steroidal antiinflammatory drugs, tramadol, opioid, ion channel blocker, diabetic neuropathy, diabetic peripheral neuropathy, peripheral neuropathy, and neuropathy. The search included Medline, Embase, EMB reviews-AP Journal club, and the Cochrane central register of controlled trials.

Study selection Randomised controlled trials comparing topically applied and orally administered drugs with a placebo in adults with painful diabetic neuropathy. Data extraction Data were extracted to examine quality of methods, characteristics of studies and patients, efficacy, and side effects. The primary outcome was dichotomous information for $50 \%$ or moderate reduction of pain. Secondary outcomes were $30 \%$ reduction of pain and withdrawals related to adverse events.

Results Odds ratios were calculated for achievement of $30 \%, 50 \%$, or moderate pain relief and for withdrawals related to adverse effects. Twenty five reports were included and seven were excluded. The 25 included reports compared anticonvulsants $(n=1270)$, antidepressants (94), opioids (329), ion channel blockers (173), $\mathrm{N}$-methyl-D-aspartate antagonist (14), duloxetine (805), capsaicin (277), and isosorbide dinitrate spray (22) with placebo. The odds ratios in terms of $50 \%$ pain relief were 5.33 (95\% confidence interval 1.77 to 16.02 ) for traditional anticonvulsants, 3.25 (2.27 to 4.66) for newer generation anticonvulsants, and 22.24 (5.83 to $84.75)$ for tricylic antidepressants. The odds ratios in terms of withdrawals related to adverse events were 1.51 (0.33 to 6.96) for traditional anticonvulsants, 2.98 (1.75 to 5.07) for newer generation anticonvulsants, and 2.32 (0.59 to 9.69) for tricylic antidepressants. Insufficient dichotomous data were available to calculate the odds ratios for ion channel blockers.

Conclusion Anticonvulsants and antidepressants are still the most commonly used options to manage diabetic neuropathy. Oral tricyclic antidepressants and traditional anticonvulsants are better for short term pain relief than newer generation anticonvulsants. Evidence of the long term effects of oral antidepressants and anticonvulsants is still lacking. Further studies are needed on opioids, $\mathrm{N}$-methyl-D-aspartate antagonists, and ion channel blockers.

\section{INTRODUCTION}

Diabetic neuropathy is a common complication of diabetes. It usually progresses gradually and involves small and large sensory fibres. The symptoms, such as loss of ability to sense pain, loss of temperature sensation, and developing neuropathic pain, follow a "glove and stocking" distribution, beginning in the lower limbs, first affecting the toes, and then progressing upward. ${ }^{1}$ The primary cause of diabetic neuropathy is thought to be hyperglycaemia. ${ }^{2}$

Diabetic neuropathy represents a major health problem worldwide. An Australian population based survey of 2436 patients with known or newly diagnosed diabetes showed that $13.1 \%$ of them had peripheral neuropathy. ${ }^{3}$ Another multicentre study in the United Kingdom showed that 22-32\% of 6363 diabetic patients had peripheral neuropathy. ${ }^{4}$ Similar results have been reported by an Italian multicentre study, which showed that $32.3 \%$ of 8757 diabetic patients had neuropathy.

Symptoms of neuropathic pain are commonly reported in patients with diabetic neuropathy. Partanen and colleagues found that among 132 patients, $7-13 \%$ had pain and paraesthesias when they were diagnosed as having type 2 diabetes mellitus. ${ }^{6}$ The prevalences of pain and of paraesthesia were $20 \%$ and $33 \% 10$ years after diagnosis. ${ }^{6}$ Sorensen and colleagues identified neuropathic pain in $11.7 \%$ of those who had insensate neuropathy and in $2.3 \%$ of those with sensate neuropathy among 2610 patients with type 2 diabetes. $^{7}$

Tight glycaemic control has been shown to be effective in slowing the progression of diabetic neuropathy. ${ }^{8-11}$ The diabetes control and complications trial in 1441 patients with type 1 diabetes showed that tight glycaemic control can delay the onset and slow the progression of neuropathy, as measured by clinical examination, autonomic testing, and nerve conduction studies. ${ }^{1011}$ Apart from glycaemic control, antidepressants and anticonvulsants are commonly used to reduce the intensity of pain in patients with painful diabetic neuropathy. 


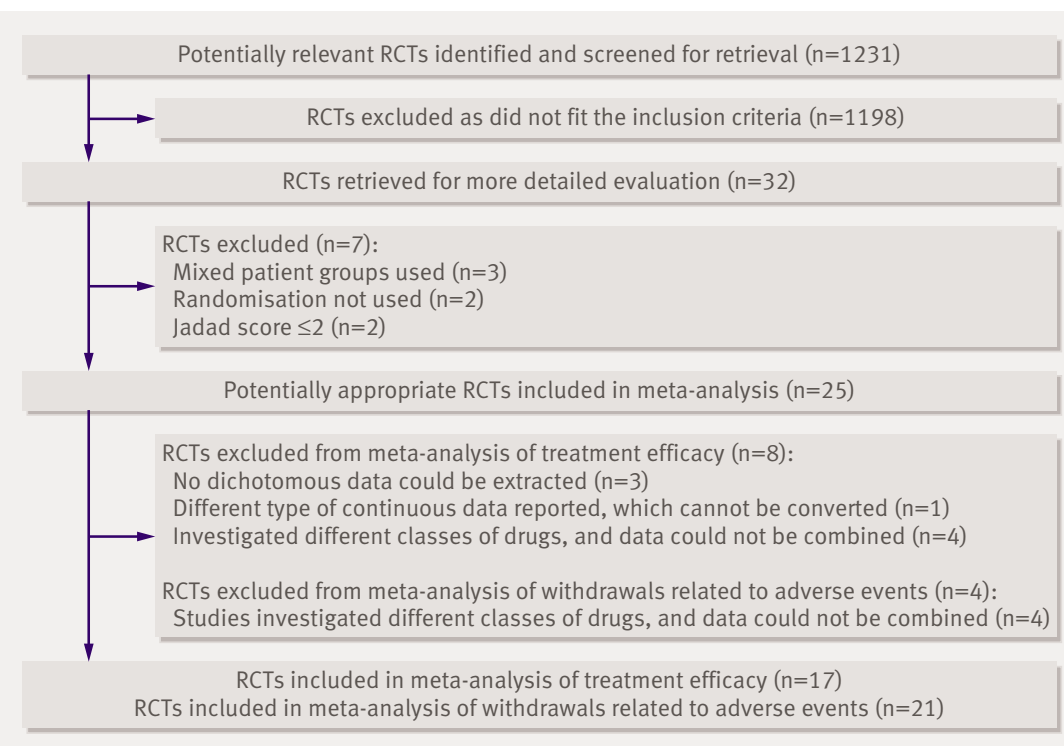

Fig 1 | Identification and inclusion of studies. RCT=randomised controlled trial

In the clinical setting, despite the use of various analgesics to manage the neuropathic pain of diabetic neuropathy, the problem persists. We did a systematic review to explore the effectiveness of analgesics in managing diabetic neuropathy.

\section{METHODS}

\section{Search strategy to identify studies}

We used several methods to identify the studies to be included. We identified randomised trials that studied analgesics used to treat diabetic neuropathy by using Medline(R) without revision from 1966 to October 2006, Embase from 1980 to October 2006, EMB
reviews-AP Journal club from 1991 to September/ October 2006, and the third quarter 2006 of the Cochrane central register of controlled trials. We identified additional reports from the reference lists of the retrieved papers.

The key words used in the search were anticonvulsant, non-steroidal anti-inflammatory drugs, ion channel blocker and neuropathy, antiepileptic/ anticonvulsant and neuropathy, antidepressant or antidepressive agents and neuropathy, tramadol and neuropathy, opioid and neuropathy, pregabalin and neuropathy, duloxetine and neuropathy, capsaicin and neuropathy, antidepressant or antidepressive agents and diabetic neuropathies or diabetic peripheral neuropathy, antidepressant or antidepressive agents and peripheral neuropathy.

\section{Selection criteria}

Participants in the studies were adults aged 18 years and above with diabetic neuropathy. The interventions involved the administration of oral or topical analgesics. The classes of drugs included paracetamol, antidepressants, opioids, non-steroidal anti-inflammatory drugs, $\mathrm{N}$-methyl-D-aspartate antagonists, tramadol, capsaicin, and anticonvulsants. The comparator was a placebo. We excluded studies comparing different classes of analgesics, such as anticonvulsants versus antidepressants. The primary and secondary outcomes of the studies had to include subjective reports of pain relief or pain intensity. We included randomised controlled trials that investigated the analgesic effects of pain relieving drugs for patients with diabetic neuropathy. We excluded reports that were non-randomised, case reports, clinical observations, or studies of intravenous analgesics, intramuscular analgesics,

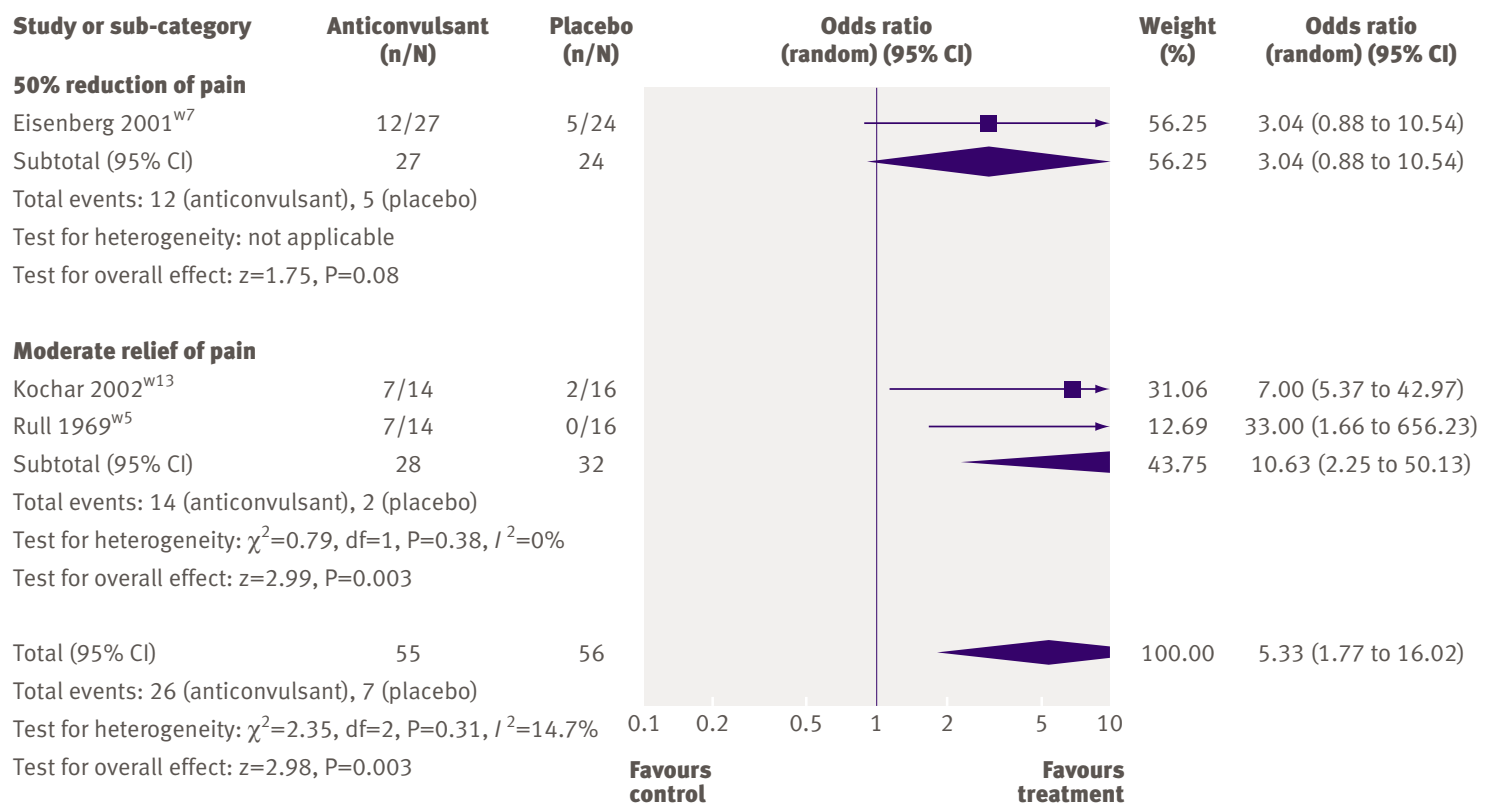




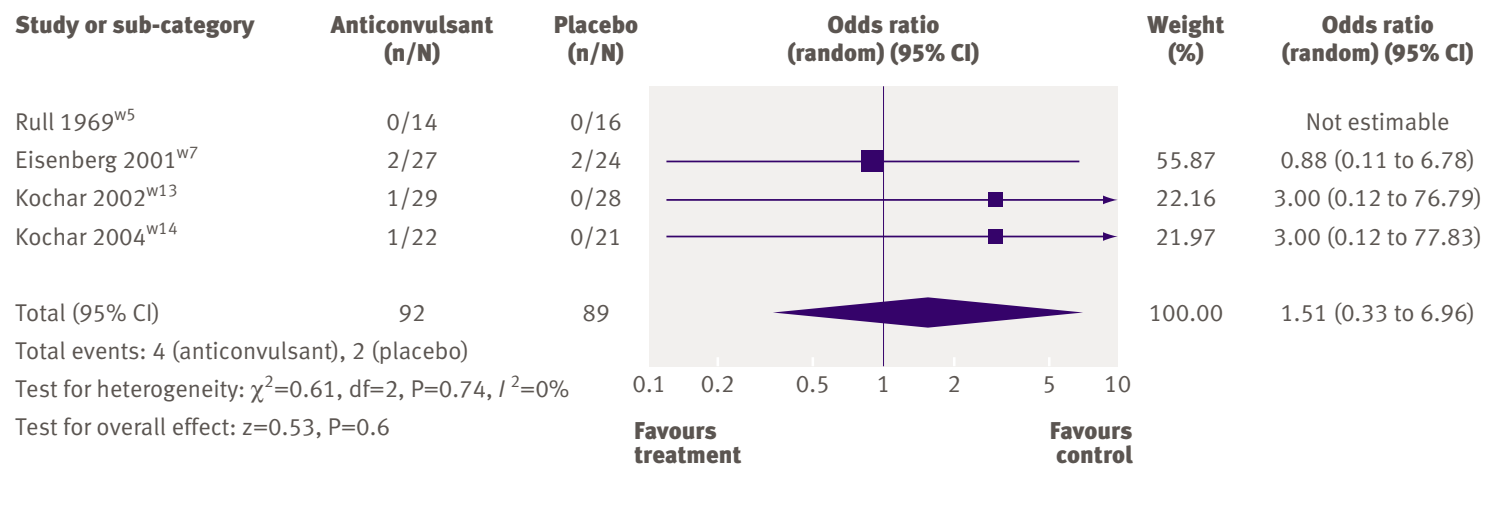

Fig 3 | Withdrawals related to adverse events for traditional anticonvulsants versus placebo

or Chinese herbal medicine. We included full text reports published in English.

\section{Quality assessment}

We used a three item, 1-5 quality scale to score each report that met the inclusion criteria. ${ }^{12}$ We excluded studies without randomisation and blinding and trials with a quality score of 2 or less. We also assessed use of concealment and intention to treat analysis. Lastly, we did not consider trials with a sample size under 10 . Two of the three reviewers made quality assessments, and disputes were settled by consensus.

\section{Data extraction}

We selected studies for retrieval from the library by reviewing the information from the title and abstract against our inclusion criteria. On the basis of their titles, we retrieved studies identified from the reference list of the available articles. We compared full reports of the studies with the inclusion criteria to determine their relevance to the systematic review. Two reviewers extracted data independently to examine characteristics of studies and patients, efficacy, and side effects.

We sent 25 letters to authors for further information on their published reports, including method of randomisation, concealment, double blinding, outcome measures, and reason for dropouts. Two of them replied. ${ }^{\mathrm{w} 1 \mathrm{w} 2}$

\section{Outcome}

We defined clinical success as about a $50 \%$ reduction in pain. This was the number of patients with a "moderate," "good," or "notable" improvement in global assessment of treatment or at least moderate pain relief on a suitable categorical scale. Secondary outcomes were $30 \%$ reduction in pain and the number of patients who withdrew as a result of adverse events.

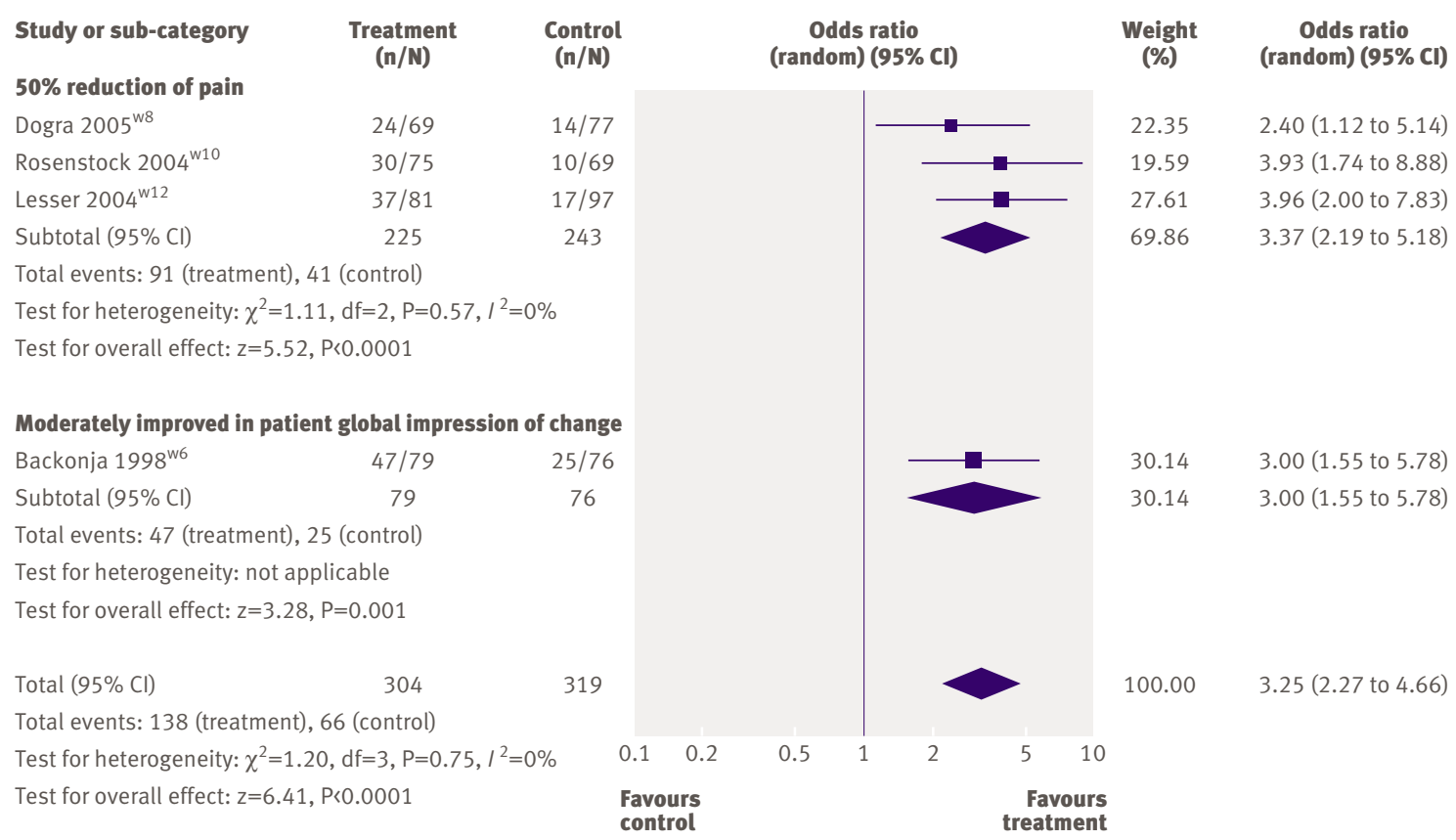




\begin{tabular}{|c|c|c|c|c|c|c|c|c|c|c|c|}
\hline \multicolumn{12}{|c|}{ Characteristics of included studies } \\
\hline Drug class & Trial & Active drug & Daily dose $(\mathrm{mg})$ & No & $\begin{array}{c}\text { Age } \\
\text { (mean) }\end{array}$ & Design & $\begin{array}{l}\text { Jadad } \\
\text { score }\end{array}$ & Concealment & $\mathrm{ITT}{ }^{*}$ & $\begin{array}{l}\text { Treatment } \\
\text { period }\end{array}$ & $\begin{array}{l}\text { Follow-up (efficacy } \\
\text { of treatment) }\end{array}$ \\
\hline \multicolumn{12}{|l|}{ Topical treatment } \\
\hline Capsaicin cream & $\begin{array}{l}\text { Capsaicin study } \\
\text { group } 1991^{\text {w3 }}\end{array}$ & $0.075 \%$ capsaicin & $\begin{array}{l}\text { Apply four times } \\
\text { daily }\end{array}$ & 277 & 60 & Parallel & 4 & NM & $\begin{array}{l}\text { Yes } \\
\text { (for } \\
\text { PGE) }\end{array}$ & 8 weeks & Completion of treatment \\
\hline $\begin{array}{l}\text { Isosorbide } \\
\text { dinitrate spray }\end{array}$ & Yuen $2002^{\text {w/4 }}$ & Isosorbide dinitrate & $\begin{array}{l}\text { Spray both feet } \\
\text { with } 30 \mathrm{mg} \\
\text { before bedtime }\end{array}$ & 22 & 63.7 & $\begin{array}{l}\text { Crossover, } \\
\text { two week } \\
\text { washout }\end{array}$ & 4 & NM & No & 4 weeks & Completion of treatment \\
\hline \multicolumn{12}{|l|}{ Oral treatment } \\
\hline \multirow[t]{10}{*}{ Anticonvulsant } & Rull $1969^{\text {w5 }}$ & Carbamazepine & $200-600$ & 30 & 54.2 & $\begin{array}{l}\text { Crossover, } \\
\text { no washout }\end{array}$ & 4 & NM & No & 2 weeks & Completion of treatment \\
\hline & Backonja $1998^{w 6}$ & Gabapentin & 3600 & 165 & 53 & Parallel & 5 & NM & Yes & 8 weeks & Completion of treatment \\
\hline & Eisenberg $2001^{\mathrm{w} 7}$ & Lamotrigine & $25-400$ & 59 & 55 & Parallel & 3 & NM & No & 8 weeks & Completion of treatment \\
\hline & Dogra $2005^{\mathrm{w} 8}$ & Oxcarbazepine & 1445 (mean) & 146 & 60 & Parallel & 5 & Yes & Yes & 16 weeks & Completion of treatment \\
\hline & Beydoun $2006^{\text {w9 }}$ & Oxcarbazepine & $\begin{array}{c}600 / 1200 / \\
1800\end{array}$ & 347 & 60 & Parallel & 5 & Yes & Yes & 16 weeks & Completion of treatment \\
\hline & $\begin{array}{l}\text { Rosenstock } \\
2004^{\mathrm{w} 10}\end{array}$ & Pregabalin & 300 & 146 & 59.7 & Parallel & 5 & Yes & No & 8 weeks & Completion of treatment \\
\hline & Richter $2005^{\mathrm{w11}}$ & Pregabalin & $150 / 600$ & 246 & 57 & Parallel & 5 & NM & Yes & 6 weeks & Completion of treatment \\
\hline & Lesser $2004^{\mathrm{w12}}$ & Pregabalin & $75 / 300 / 600$ & 337 & 59.9 & Parallel & 5 & Yes & Yes & 5 weeks & $\begin{array}{l}\text { Five weeks for double } \\
\text { blind period }\end{array}$ \\
\hline & Kochar $2002^{\text {w13 }}$ & Sodium valproate & 1200 & 57 & 56 & Parallel & 3 & Yes & Yes & 4 weeks & Completion of treatment \\
\hline & Kochar $2004^{\text {w14 }}$ & Sodium valproate & 1000 & 43 & 55 & Parallel & 5 & NM & No & 3 months & Completion of treatment \\
\hline \multicolumn{12}{|l|}{ Antidepressant: } \\
\hline \multirow[t]{3}{*}{ TCA } & $\operatorname{Max} 1987^{\mathrm{w15}}$ & Amitriptyline & $25-100$ & 37 & $\begin{array}{c}57 \\
\text { (med- } \\
\text { ian) }\end{array}$ & $\begin{array}{l}\text { Crossover, } \\
\text { no washout }\end{array}$ & 4 & NM & No & 6 weeks & Completion of treatment \\
\hline & $\operatorname{Max} 1991^{\mathrm{w} 16}$ & Desipramine & 201 (mean) & 24 & $\begin{array}{c}62 \\
\text { (med- } \\
\text { ian) }\end{array}$ & $\begin{array}{l}\text { Crossover, } \\
\text { no washout }\end{array}$ & 4 & NM & No & 6 weeks & Completion of treatment \\
\hline & Kvinesdal $1984^{\text {w17 }}$ & Imipramine & 100 & 15 & 54 & $\begin{array}{l}\text { Crossover, } \\
\text { no washout }\end{array}$ & 4 & NM & No & 5 weeks & Completion of treatment \\
\hline SSRI & Sindrup $1992^{\mathrm{w} 1}$ & Citalopram & 40 & 18 & $\begin{array}{c}56 \\
\text { (med- } \\
\text { ian) }\end{array}$ & $\begin{array}{l}\text { Crossover, } \\
\text { one week } \\
\text { washout }\end{array}$ & 4 & NM & No & 3 weeks & Completion of treatment \\
\hline \multirow[t]{2}{*}{ SNRI } & Goldstein $2005^{\text {w18 }}$ & Duloxetine & $20 / 60 / 120$ & 457 & 60 & Parallel & 4 & Yes & Yes & 12 weeks & Completion of treatment \\
\hline & Raskin $2005^{\text {w19 }}$ & Duloxetine & $60 / 120$ & 348 & 58.8 & Parallel & 5 & Yes & Yes & 12 weeks & Completion of treatment \\
\hline \multirow[t]{3}{*}{$\begin{array}{l}\text { Ion channel } \\
\text { blocker }\end{array}$} & Dejgard $1988^{\text {w20 }}$ & Mexiletine & $10 \mathrm{mg} / \mathrm{kg}$ & 16 & $\begin{array}{c}50 \\
\text { (med- } \\
\text { ian) }\end{array}$ & $\begin{array}{l}\text { Crossover, } \\
\text { four week } \\
\text { washout }\end{array}$ & 3 & NM & No & 10 weeks & Completion of treatment \\
\hline & $\begin{array}{l}\text { Oskarsson } \\
1997^{\mathrm{w} 21}\end{array}$ & Mexiletine & $225 / 450 / 675$ & 126 & 53.5 & Parallel & 3 & NM & No & 3 weeks & Completion of treatment \\
\hline & Wright $1997^{\text {w22 }}$ & Mexiletine & 600 & 31 & 50 & Parallel & 3 & NM & Yes & 3 weeks & $\begin{array}{l}\text { Upon completing } \\
\text { treatment }\end{array}$ \\
\hline NMDA antagonist & Nelson $1997^{\text {w23 }}$ & Dextromethorphan & 381 (mean) & 14 & $\begin{array}{c}54 \\
\text { (med- } \\
\text { ian) }\end{array}$ & $\begin{array}{l}\text { Crossover, } \\
\text { one week } \\
\text { washout }\end{array}$ & 5 & NM & No & 6 weeks & Completion of treatment \\
\hline \multirow[t]{3}{*}{ Opioid } & Gimbel $2003^{\text {w24 }}$ & $\begin{array}{l}\text { Controlled release } \\
\text { oxycodone }\end{array}$ & $10-120$ & 159 & 59 & Parallel & 5 & Yes & Yes & 42 days & Completion of treatment \\
\hline & Watson $2003^{\text {w2 }}$ & $\begin{array}{l}\text { Controlled release } \\
\text { oxycodone }\end{array}$ & $10-80$ & 45 & 63 & $\begin{array}{l}\text { Crossover, } \\
\text { no washout }\end{array}$ & 5 & Yes & Yes & 4 weeks & Completion of treatment \\
\hline & Harati $1998^{\mathrm{w} 25}$ & Tramadol & $200-400$ & 125 & 59 & Parallel & 5 & Yes & Yes & 42 days & Completion of treatment \\
\hline
\end{tabular}

ITT=intention to treat analysis; NM=not mentioned; NMDA=N-methyl-D-aspartate; PGE=physician's global evaluation; SNRI=serotonin noradrenaline reuptake inhibitor; SSRI=selective serotonin reuptake inhibitor; TCA=tricyclic antidepressant.

Data analysis

We combined the results and expressed them as odds ratios with 95\% confidence intervals, using a random effect model, for the studies with sufficient data. We used Review Manager 4.2 for all statistical calculations. We assessed homogeneity with the $I^{2}$ statistic for studies with sufficient data, and for the studies without sufficient data we assessed homogeneity visually. We based a subgroup analysis on different classes of drugs We followed QUOROM guidelines. ${ }^{13}$

\section{RESULTS}

\section{Description of the studies}

We screened 1231 citations for eligibility; we identified no eligible study on non-steroidal anti-inflammatory drugs. We retrieved 32 full text articles published in 


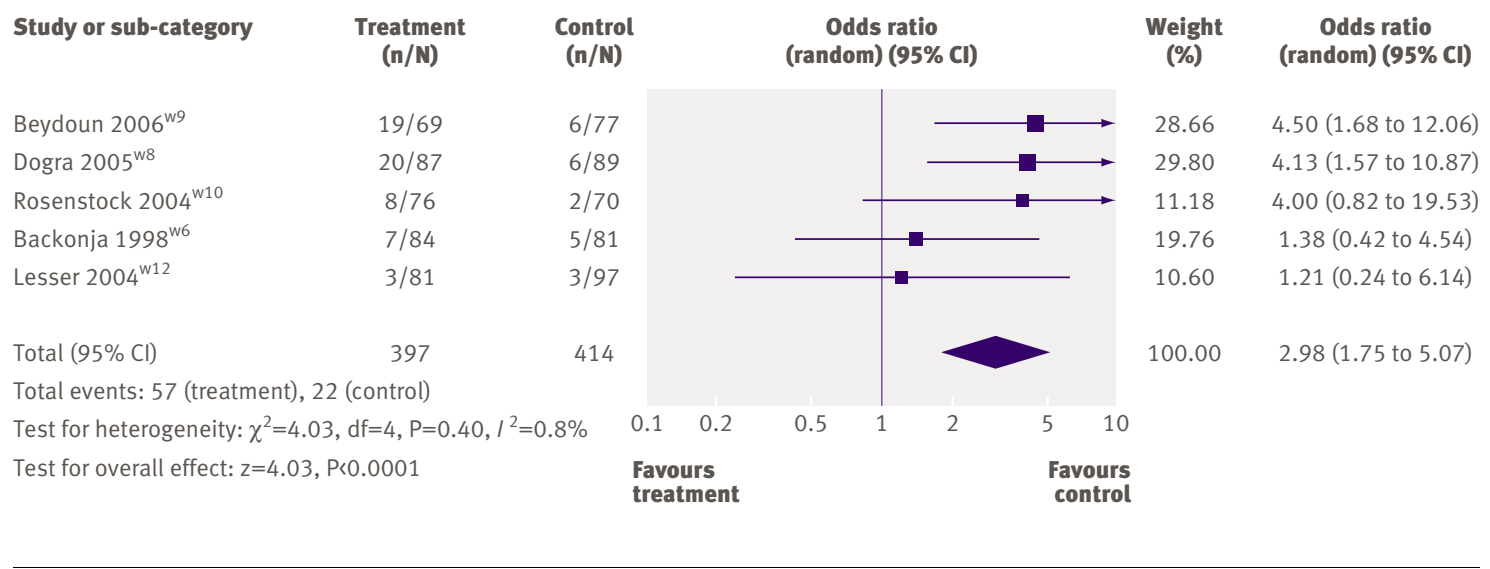

Fig 5 | Withdrawals related to adverse events for newer generation anticonvulsants versus placebo

English. Three studies used mixed patient groups, ${ }^{14-16}$ two studies did not use randomisation, ${ }^{1718}$ and the Jadad score was $\leq 2$ in two studies ${ }^{1920}$; we excluded all these studies. Finally, we included 25 articles that met the inclusion criteria, ${ }^{\mathrm{wl}-\mathrm{w} 25}$ and 17 of them were included in the meta-analysis of treatment efficacy (fig 1). The table shows the characteristics and methodological quality of the included studies.

\section{Anticonvulsants}

Ten trials, with a total of 1576 patients, investigated traditional and newer generation anticonvulsants, including sodium valproate, ${ }^{\text {w13 w14 }}$ gabapentin, ${ }^{\text {w6 }}$ lamotrigine, ${ }^{\mathrm{w} 7}$ carbamazepine, ${ }^{\mathrm{w} 5}$ pregabalin, ${ }^{\text {w10-w12 }}$ and oxcarbazepine. $^{\text {w8 } \mathrm{w} 9}$ The carbamazepine trial used a crossover design. Two of the pregabalin studies and one of the oxcarbazepine studies were dose response trials. $^{\mathrm{w} 9 \mathrm{w} 11 \mathrm{w} 12}$ The treatment period varied from two weeks to three months. We extracted no efficacy data

\begin{tabular}{|c|c|c|c|c|c|c|c|c|c|c|}
\hline \multirow{2}{*}{\multicolumn{2}{|c|}{ 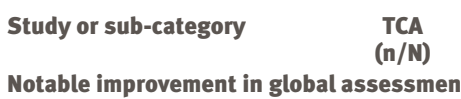 }} & \multirow[t]{2}{*}{$\begin{array}{c}\text { Placebo } \\
\text { (n/N) }\end{array}$} & & \multicolumn{4}{|c|}{$\begin{array}{c}\text { Odds ratio } \\
\text { (random) }(95 \% \mathrm{Cl})\end{array}$} & \multirow{2}{*}{\multicolumn{2}{|c|}{$\begin{array}{l}\text { Weight } \\
\text { (\%) }\end{array}$}} & \multirow[t]{2}{*}{$\begin{array}{c}\text { Odds ratio } \\
\text { (random) }(95 \% \mathrm{Cl})\end{array}$} \\
\hline & & & & & & & & & & \\
\hline Kvinesdal $1984^{\text {w17 }}$ & $7 / 12$ & $0 / 12$ & & & & & & $\longrightarrow$ & 19.26 & 34.09 (1.64 to 707.92$)$ \\
\hline Subtotal $(95 \% \mathrm{Cl})$ & 12 & 12 & & & & & & & 19.26 & 34.09 (1.64 to 707.92$)$ \\
\hline \multicolumn{11}{|c|}{ Total events: 7 (TCA), 0 (placebo) } \\
\hline \multicolumn{11}{|c|}{ Test for heterogeneity: not applicable } \\
\hline \multicolumn{11}{|c|}{ Test for overall effect: $\mathrm{z}=2.28, \mathrm{P}=0.02$} \\
\hline \multicolumn{11}{|l|}{ Moderate relief of pain } \\
\hline $\operatorname{Max} 1987^{w 15}$ & $19 / 29$ & $0 / 29$ & & & & & & $\rightarrow$ & 21.14 & 109.57 (6.06 to 1979.71$)$ \\
\hline $\operatorname{Max} 1991^{\mathrm{w} 16}$ & $11 / 20$ & $2 / 20$ & & & & & & & 59.60 & $11.00(2.00$ to 60.57$)$ \\
\hline Subtotal $(95 \% \mathrm{Cl})$ & 49 & 49 & & & & & & & 80.74 & 26.16 (2.67 to 256.42$)$ \\
\hline \multicolumn{11}{|c|}{ Total events: 30 (TCA), 2 (placebo) } \\
\hline \multicolumn{11}{|c|}{ Test for heterogeneity: $\chi^{2}=1.97, \mathrm{df}=1, \mathrm{P}=0.16, /^{2}=49.1 \%$} \\
\hline \multicolumn{11}{|c|}{ Test for overall effect: $\mathrm{z}=2.80, \mathrm{P}=0.005$} \\
\hline Total $(95 \% \mathrm{Cl})$ & 61 & 61 & & & & & & $\longrightarrow$ & 100.00 & $22.24(5.83$ to 84.75$)$ \\
\hline \multicolumn{11}{|c|}{ Total events: 37 (TCA), 2 (placebo) } \\
\hline \multicolumn{3}{|c|}{ Test for heterogeneity: $\chi^{2}=2.03, \mathrm{df}=2, \mathrm{P}=0.36, /^{2}=1.5 \%$} & 0.1 & 0.2 & 0.5 & 1 & 2 & 10 & & \\
\hline \multicolumn{3}{|c|}{ Test for overall effect: $z=4.54, P<0.0001$} & $\begin{array}{l}\text { Favo } \\
\text { cont }\end{array}$ & & & & & $\begin{array}{r}\text { Favours } \\
\text { treatment }\end{array}$ & & \\
\hline
\end{tabular}

from one of the studies on sodium valproate. ${ }^{\mathrm{w} 14} \mathrm{We}$ extracted data on $300 \mathrm{mg}$ pregabalin, $1200 \mathrm{mg}$ oxcarbazepine, and the first treatment period in the carbamazepine trial for meta-analysis. ${ }^{\mathrm{w} 5 \mathrm{w} 9 \mathrm{w} 10 \mathrm{w} 12} \mathrm{We}$ analysed data on $600 \mathrm{mg}$ pregabalin separately. ${ }^{\mathrm{w} 11 \mathrm{w} 12} \mathrm{We}$ categorised anticonvulsants into two groups-traditional anticonvulsants and newer generation anticonvulsants.

The pooled odds ratio of treatment efficacy with traditional anticonvulsants was $5.33(95 \%$ confidence interval 1.77 to 16.02 ) (fig 2). The pooled odds ratio for withdrawal related to adverse events with traditional anticonvulsants was 1.51 (0.33 to 6.96) (fig 3).

The pooled odds ratio of treatment efficacy with newer generation anticonvulsants was 3.25 (2.27 to 4.66) (fig 4). The pooled odds ratio for withdrawal related to adverse events with newer generation anticonvulsants was 2.98 (1.75 to 5.07) (fig 5).

The odds ratios in terms of $50 \%$ pain relief with pregabalin $600 \mathrm{mg}$ daily and pregabalin $300 \mathrm{mg}$ daily were 


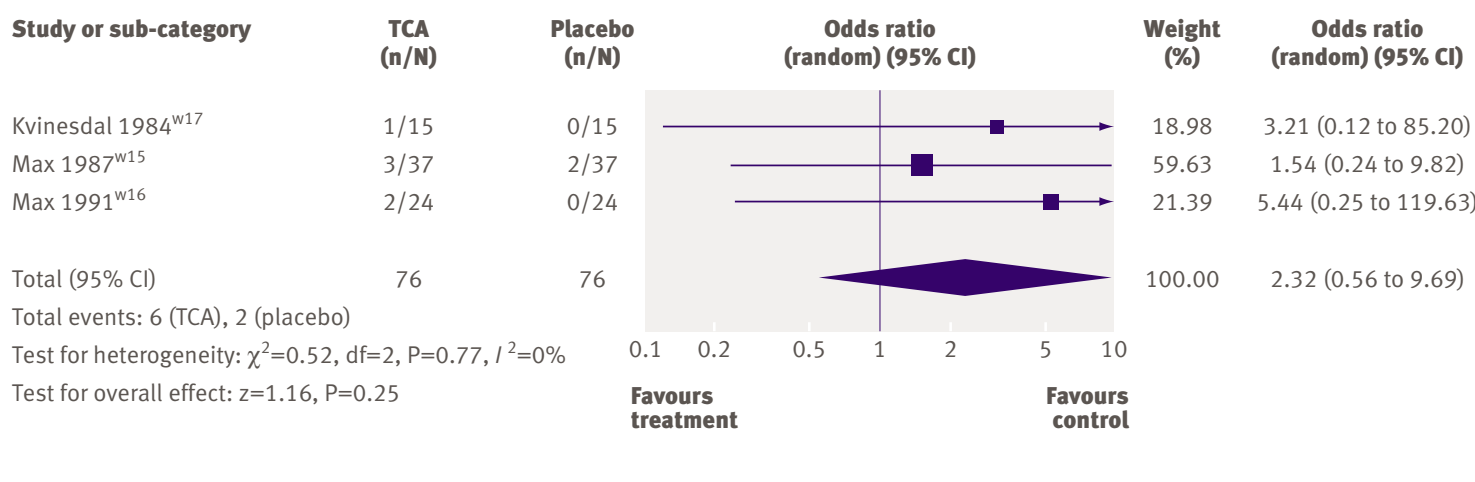

Fig 7 | Withdrawals related to adverse events for tricyclic antidepressants (TCA) versus placebo

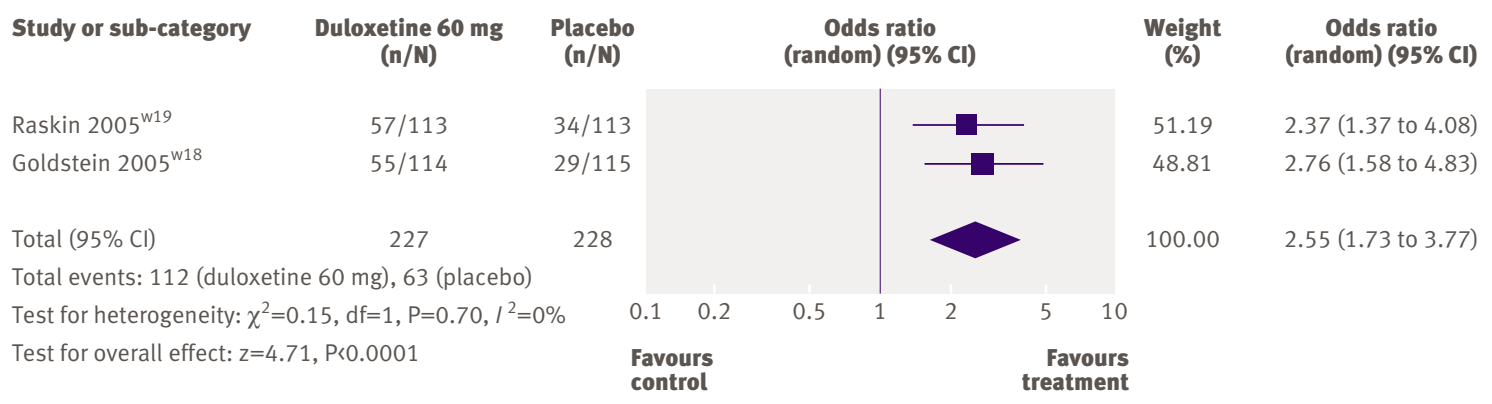

Fig $8 \mid$ Treatment efficacy of duloxetine $60 \mathrm{mg}$ versus placebo

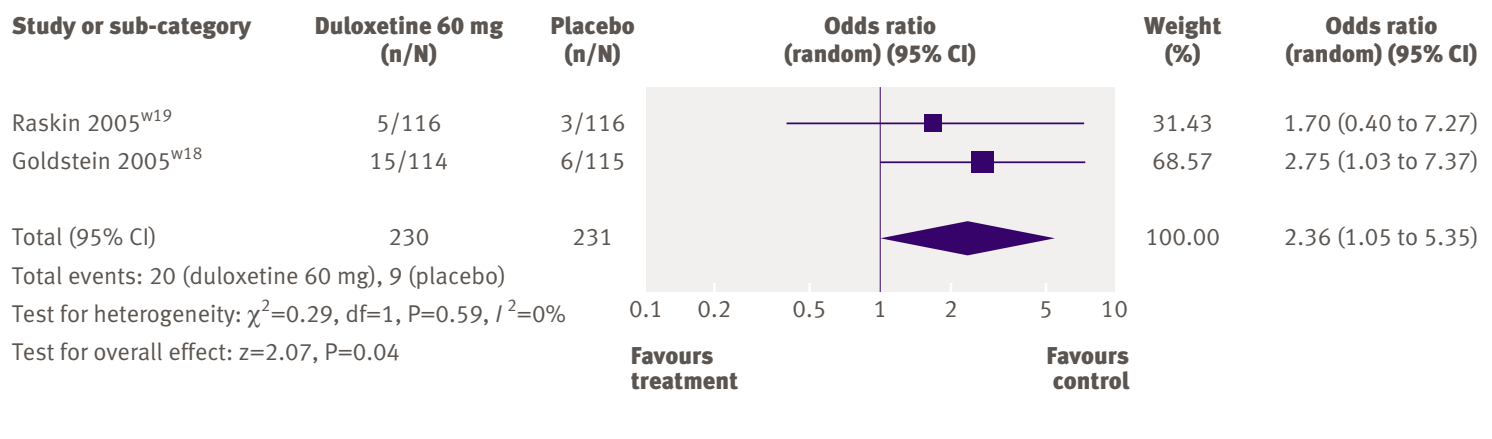

Fig $9 \mid$ Withdrawals related to adverse events for duloxetine $60 \mathrm{mg}$ versus placebo

3.96 (2.5 to 5.55$)$ and 3.95 (2.34 to 6.66 ). The odds ratios in terms of withdrawal related to adverse effects were 2.81 (1.13 to 7.04 ) for pregabalin $600 \mathrm{mg}$ daily and 2.23 (0.68 to 7.26 ) for pregabalin $300 \mathrm{mg}$ daily. The odds ratios in terms of $30 \%$ pain relief with pregabalin $300 \mathrm{mg}$ and $600 \mathrm{mg}$ daily were 3.28 and 3.84 . The odds ratio in terms of $30 \%$ pain relief with oxcarbazepine $1445 \mathrm{mg}$ was 2.04 .

The common side effects from use of anticonvulsants were somnolence and dizziness, and the major adverse reaction was liver derangement. Two participants withdrew from studies because of liver derangement. ${ }^{\text {w13 w14 }}$

\section{Antidepressants}

Four trials with a total of 94 patients investigated the tricyclic antidepressants desipramine, ${ }^{\mathrm{w} 16}$ imipramine, ${ }^{\mathrm{w} 17}$ and amitriptyline $\mathrm{w}^{\mathrm{w} 15}$ and the selective serotonin reuptake inhibitor citalopram. ${ }^{\mathrm{wl}}$ All of them were crossover studies with treatment periods between three and six weeks. Only one study had a one week washout period: we extracted the data from both treatment periods of this study. ${ }^{\mathrm{w1}}$

Although we could extract no data from the published report on citalopram, this study used published data from a previous study. ${ }^{21}$ The odds ratio in terms of $50 \%$ pain relief with citalopram was 3.5 (0.3 to 38.2 ), and the odds ratio for withdrawal related to adverse events was 5.6 (0.3 to 125.5). The pooled odds ratio for treatment efficacy of tricyclic antidepressants was 22.24 (5.83 to 84.75) (fig 6). The pooled odds ratio for adverse effect related withdrawal from tricyclic antidepressants was 2.32 (0.59 to 9.69) (fig 7). The most common adverse effect related to withdrawal was dry mouth and sedation. 
Serotonin noradrenaline reuptake inhibitor

Two trials with a total of 805 patients investigated duloxetine. ${ }^{\text {w18 w19 }}$ Both trials used a 12 week parallel group design, and both of them were dose response trials. The pooled odds ratio in terms for $50 \%$ pain relief with duloxetine $60 \mathrm{mg}$ was 2.55 (1.73 to 3.77 ) (fig 8), and the odds ratio for withdrawal related to adverse events was 2.36 (1.05 to 5.35) (fig 9). For duloxetine $120 \mathrm{mg}$, the odds ratios were 2.10 (1.03 to 4.27 ) for $50 \%$ pain relief (fig 10) and 4.65 (2.18 to 9.94) for withdrawal related to adverse events (fig 11). The most frequently reported adverse events were nausea, somnolence, dizziness, and constipation.

\section{Ion channel blockers}

Three trials investigated mexiletine in a total of 173 patients. One trial used a crossover design, ${ }^{\text {w20 }}$ and another was a dose response study. ${ }^{\text {w21 }}$ The pooled weighted mean difference of the mean score on a visual analogue scale for pain intensity for mexiletine $600 \mathrm{mg}$ and $720 \mathrm{mg}$ versus placebo was $-1.87(-2.64$ to -1.11$)$ (fig 12). One study reported no statistical differences between mexiletine $600-675 \mathrm{mg}$ and a placebo with a three week treatment period. ${ }^{\text {w22 }}$

The pooled odds ratio for adverse effect related withdrawal from mexiletine was 1.08 (0.13 to 8.80) (fig 13). The adverse effects related to withdrawal were itching, pain, headache, nausea, and vomiting. ${ }^{\text {w22 }}$

\section{$\mathrm{N}$-methyl-D-aspartate antagonists}

Only one trial, with a total of 14 patients, investigated dextromethorphan. ${ }^{\text {w23 }}$ This trial used a crossover design, with a six week treatment period and a one week washout. We could not extract the data for the first treatment period, so we based the calculation on the data for the whole treatment period. The odds ratio

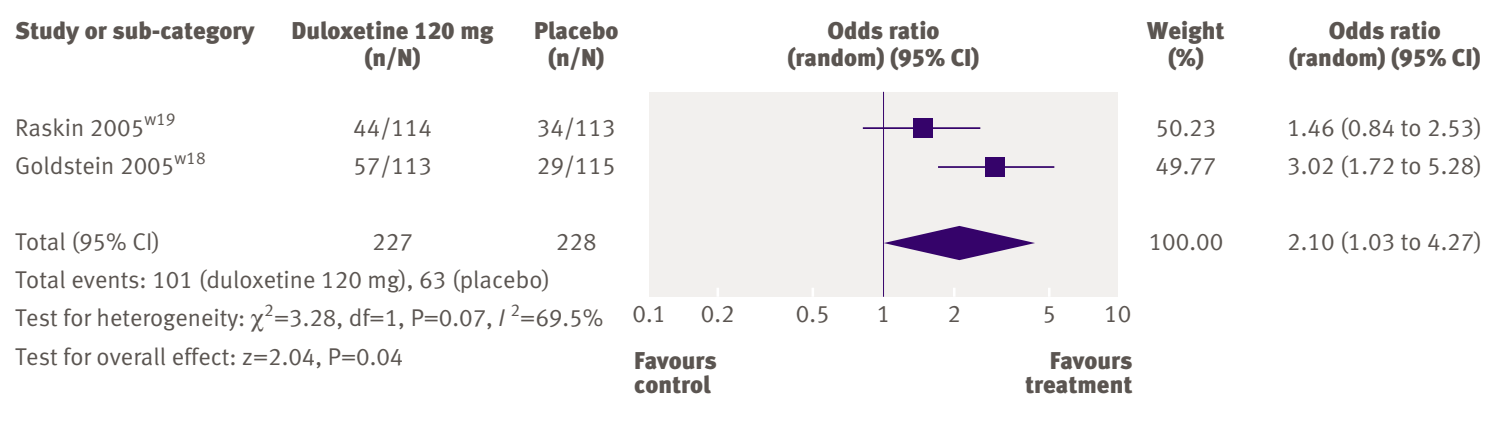

Fig 10 | Treatment efficacy of duloxetine $120 \mathrm{mg}$ versus placebo

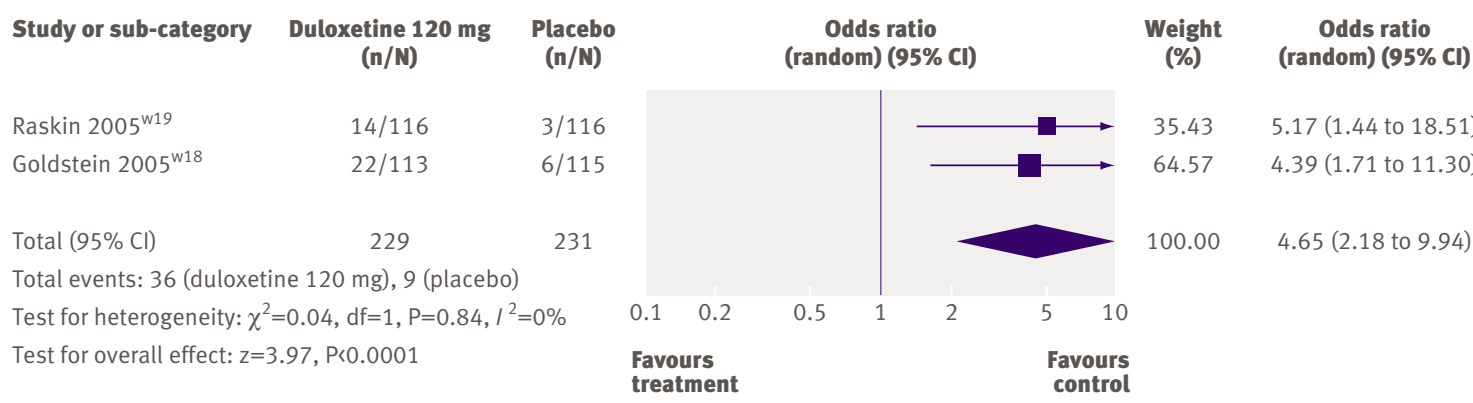

Fig 11 | Withdrawals related to adverse events for duloxetine $120 \mathrm{mg}$ versus placebo

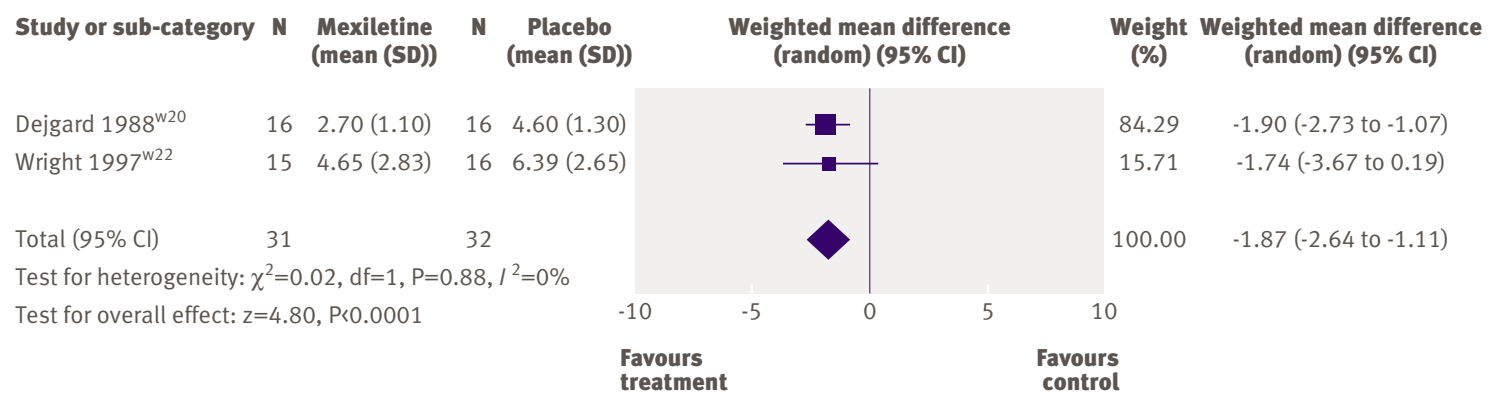




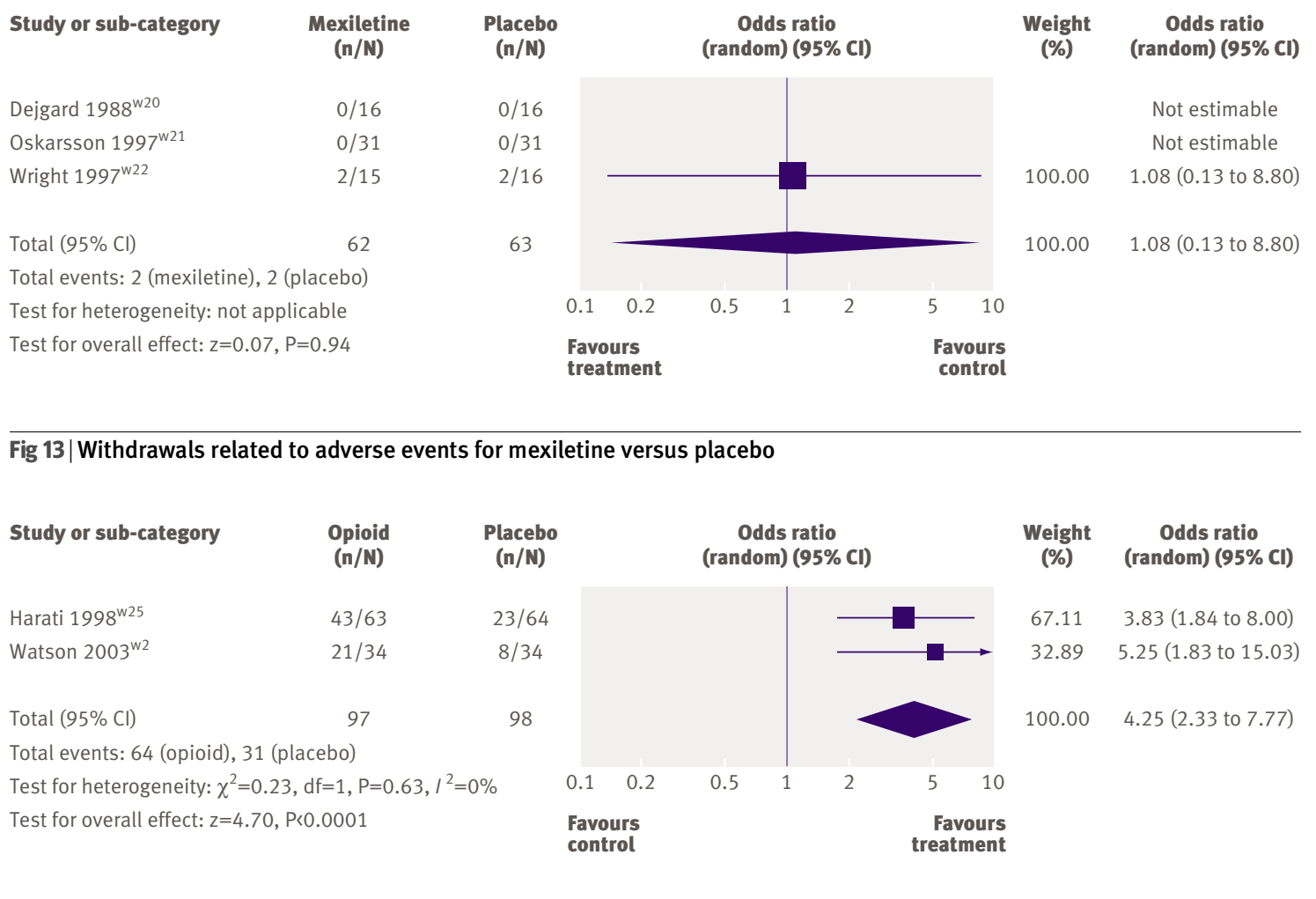

Fig 14 | Treatment efficacy of opioids versus placebo

\begin{tabular}{|c|c|c|c|c|c|c|c|c|}
\hline Study or sub-category & $\begin{array}{l}\text { Opioid } \\
\text { (n/N) }\end{array}$ & \multirow{2}{*}{$\begin{array}{c}\text { Placebo } \\
\text { (n/N) } \\
1 / 64\end{array}$} & \multicolumn{4}{|c|}{$\begin{array}{c}\text { Odds ratio } \\
\text { (random) }(95 \% \mathrm{Cl})\end{array}$} & \multirow[t]{2}{*}{$\begin{array}{l}\text { Weight } \\
\text { (\%) }\end{array}$} & \multirow{2}{*}{$\begin{array}{c}\begin{array}{c}\text { Odds ratio } \\
\text { (random) }(\mathbf{9 5 \%} \mathbf{~ C l})\end{array} \\
10.50(1.29 \text { to } 85.55)\end{array}$} \\
\hline Harati $1998^{\text {w25 }}$ & $9 / 63$ & & & & & & & \\
\hline Gimbel $2003^{\text {w24 }}$ & $7 / 82$ & $4 / 77$ & & & & & 48.61 & $1.70(0.48$ to 6.07$)$ \\
\hline Watson $2003^{\text {w2 }}$ & $7 / 42$ & $1 / 45$ & & & & & 25.32 & $8.11(0.95$ to 68.87$)$ \\
\hline Total $(95 \% \mathrm{Cl})$ & 190 & 186 & & & & & 100.00 & $4.06(1.16$ to 14.21$)$ \\
\hline \multicolumn{9}{|c|}{ Total events: 23 (opioid), 6 (placebo) } \\
\hline \multicolumn{3}{|c|}{ Test for heterogeneity: $\chi^{2}=2.99, \mathrm{df}=2, \mathrm{P}=0.22, I^{2}=33.0 \%$} & $0.1 \quad 0.2$ & 0.5 & 2 & 10 & & \\
\hline \multicolumn{3}{|c|}{ Test for overall effect: $z=2.19, P=0.03$} & $\begin{array}{l}\text { Favours } \\
\text { treatment }\end{array}$ & \multicolumn{5}{|c|}{$\begin{array}{l}\text { Favours } \\
\text { control }\end{array}$} \\
\hline
\end{tabular}

Fig 15 | Withdrawals related to adverse events of opioids versus placebo

in terms of $50 \%$ pain relief with a mean daily dose of $381 \mathrm{mg}$ dextromethorphan was 31.2 (1.5 to 633.1 ). No extractable dichotomous data on adverse events related to withdrawal have been published.

\section{Opioids}

Three trials with a total of 329 patients investigated controlled release oxycodone and tramadol. ${ }^{\mathrm{w} 2 \mathrm{w} 24 \mathrm{w} 25}$ One of the controlled release oxycodone trials used a crossover design. ${ }^{\mathrm{w} 2}$ In another trial, a $37 \mathrm{mg}$ average daily dose of controlled release oxycodone reportedly had a superior analgesic effect compared with placebo. ${ }^{\text {w24 }}$

Although we could extract no data from the published report on tramadol, this study used and published data from a previous study. ${ }^{21}$ The odds ratio of $50 \%$ pain relief was 3.8 (1.8 to 8.0$)$ for tramadol at an average daily dose of $210 \mathrm{mg}$. The pooled odds ratio for treatment efficacy of opioids was 4.25 (2.33 to 7.77) (fig 14).

The pooled odds ratio for withdrawal from opioids related to adverse events was 4.06 (1.16 to 14.21) (fig 15). The most common adverse events related to use of controlled release oxycodone were constipation, somnolence, and nausea. The withdrawal related adverse events for tramadol were dyspepsia and nausea. Common adverse events related to use of tramadol were nausea, constipation, headache, and somnolence.

\section{Topical agents}

One trial with a total of 22 patients investigated isosorbide dinitrate spray. ${ }^{\mathrm{w} 4}$ This trial used a crossover design, with a four week treatment period and a two week washout. However, we could extract no 


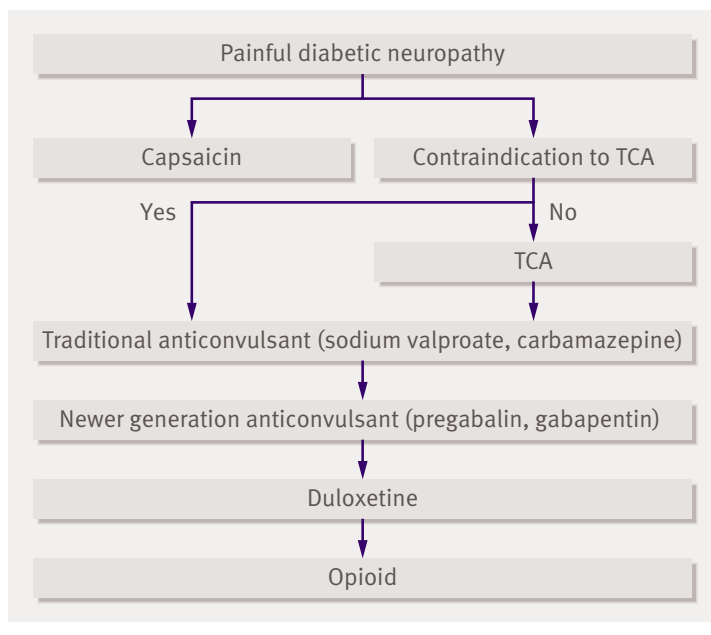

Fig 16 | Proposed treatment algorithm for painful diabetic neuropathy

dichotomous data from the published reports. The author reported that significant relief from burning sensation occurred in the treatment group.

One trial with a total of 277 patients investigated $0.075 \%$ capsaicin cream. ${ }^{\text {w3 }}$ This trial used an eight week parallel group design, and the capsaicin cream was applied to the skin four times daily. The odds ratio in terms of $50 \%$ pain relief was 2.37 (1.32 to $4.26)$, and the odds ratio of withdrawal related to adverse events was 4.02 (1.45 to 11.16). The most common adverse events were a burning sensation at the site of application, coughing or sneezing, accidental irritation to other body parts, and rashes.

\section{DISCUSSION}

Our systematic review shows that tricyclic antidepressants, traditional anticonvulsants, and opioids have better efficacy than newer generation anticonvulsants, a selective serotonin reuptake inhibitor, and a serotonin noradrenaline reuptake inhibitor for relieving the pain of diabetic neuropathy. Most trials were of good methodological quality, although sample size was small and some of the trials used a crossover design without a washout period.

Some of the trials included in this review used the crossover method; only four of them mentioned using a washout period. In a study with no washout period, the carryover effect may not be eliminated from the first period of the treatment effect; we

\section{WHAT IS ALREADY KNOWN ON THIS TOPIC}

Current guidelines recommend the use of antidepressants and anticonvulsants in the treatment of painful diabetic neuropathy

\section{WHAT THIS STUDY ADDS}

Oral tricyclic antidepressants and traditional anticonvulsants are better for short term pain relief than newer generation anticonvulsants

Evidence of the long term effects of oral antidepressants and anticonvulsants is still lacking therefore used only the data from the first period to calculate the efficacy of the drugs (if we could extract the data). However, this may lead to selection bias, resulting in an underestimation of the effect of the drug. ${ }^{22}$ w3 In Rull's study, the odds ratio was 33 when calculated for the first treatment period and 18.31 when calculated for the whole treatment period. ${ }^{\text {w5 }}$ Therefore, interpretation of systematic review results should be cautious when both crossover and parallel studies are included.

A single study investigated $N$-methyl-D-aspartate antagonists, and estimating the effect of the drug on the basis of only one study is difficult. For ion channel blockers, three trials reported contradictory results, so we could not calculate the efficacy of this treatment. Although the odds ratio of $50 \%$ pain relief for tramadol was 3.8, that for withdrawal related to adverse events was greater for tramadol than for other treatments, which may reduce the generalisability of the findings for this drug. For anticonvulsants, the odds ratio for $50 \%$ pain relief was greater with traditional anticonvulsants than with newer generation anticonvulsants. In contrast, the odds ratio for withdrawals related to adverse events was greater for newer generation anticonvulsants than for traditional anticonvulsants. This may be related to the use of different inclusion criteria and treatment periods. Finally, the treatment period was less then six months in all of the studies, so the long term effect of these drugs cannot be judged.

Painful symptoms reported by patients with diabetic neuropathy have been frequently documented. Neuropathic pain symptoms are reported in 3-20\% of patients with diabetic neuropathy. ${ }^{672324}$ Pain paroxysms, deep aching pain, and hot or burning pain have often been described. ${ }^{2526}$ In the clinical setting, management focuses on two aspects: disease modifying treatment such as glycaemic control and the use of various kinds of analgesics to reduce the intensity of the pain. Although pain intensity may not be sufficient to reflect the outcome of treatment, it is a common outcome measure in clinical research. Few studies reported treatment efficacy for different qualities of pain such as allodynia and burning pain..$^{\mathrm{w} 4 \mathrm{w} 11 \mathrm{w} 18}$ The efficacy of drug treatment may be underestimated, especially for particular painful symptoms.

\section{Conclusions}

Although an increasing number of trials have investigated different kinds of drugs to manage neuropathic pain, anticonvulsants and antidepressants are still the options most commonly used for painful diabetic neuropathy. Long term studies of the efficacy and adverse effects of anticonvulsants and antidepressants are needed, as these drugs are commonly used in clinical setting. Further studies are needed on ion channel blockers, $N$-methyl-D-aspartate antagonists, and opioids, as well as non-pharmacological strategies. In addition, their treatment efficacy for common painful symptoms needs to be explored. Finally, we propose a treatment algorithm based on the available data (fig 16). 
Contributors: M-cW planned the review, searched the literature, selected articles, extracted and analysed the data, and drafted and revised the manuscript. JWYC initiated the review, selected articles, and extracted and analysed the data. TKSW supervised the review. All authors approved the final version. M-cW is the guarantor.

Funding: None.

Competing interests: None declared.

Ethical approval: Not needed.

1 Greene DA, Stevens MJ, Feldman EL. Diabetic neuropathy: scope of the syndrome. Am / Med 1999;107:2-8S

2 Klein C, Polydefkis M, Chandhry V. Peripheral neuropathy treatment trials. In: Biller J, Bogousslavaky J, eds. Blue books of practical neurology: clinical trials in neurologic practice. USA: ButterworthHeinemann, 2001:261-91.

3 Tapp RJ, Shaw JE, de Courtenm MP, Dunstan DW, Welborn TA, Zimmet PZ, et al. Foot complications in type 2 diabetes: an Australian population-based study. Diabet Med 2003;20:105-13.

4 Young MJ, Boulton AJM, Williams DRR, Mcleod AF, Sonksen PH. A multi-center study of the prevalence of diabetic neuropathy in patients attending UK diabetic clinics. Diabetologia 1993;36:150-4.

5 Fedele D, Comi G, Coscelli C, Cucinotta D, Feldman EL, Chirlanda G, et al. A multicenter study on the prevalence of diabetic neuropathy in Italy. Diabetes Care 1997;20:836-43.

6 Partanen J, Niskanen L, Lehtinen J, Mervaala E, Siitonen O, Uusitupa M. Natural history of peripheral neuropathy in patients with non-insulin-dependent diabetes mellitus. N Engl J Med 1995:333:89-94.

7 Sorensen L, Molyneaux L, Yue DK. Insensate versus painful diabetic neuropathy: the effects of height, gender, ethnicity and glycemic control. Diabetes Res Clin Pract 2002;57:45-51.

8 Ohkubo Y, Kishikawa H, Araki E, Miyata T, Isami S, Motoyoshi S, et al. Intensive insulin therapy prevents the progression of diabetic microvascular complications in Japanese patients with non-insulindependent diabetes mellitus: a randomized prospective 6-year. Diabetes Res Clin Pract 1995;28:103-17.

9 Reichard P, Nilsson BY, Rosenqvist U. The effect of long-term intensified insulin treatment on the development of microvascular complications of diabetes mellitus. N Engl/Med 1993;329:304-9.

10 Diabetes Control and Complications Trial Research Group. The effect of intensive treatment of diabetes on the development and progression of long-term complications in insulin-dependent diabetes mellitus. N Engl J Med 1993;329:977-86.

11 Diabetes Control and Complications Trial Research Group. The effect of intensive diabetes treatment on the development and progression of neuropathy. Ann Intern Med 1995;122:561-8.

12 Jadad AR, Moore A, Carroll D, Jenkinson C, Reynolds DJM, Gavaghan DJ, et al. Assessing the quality of reports of randomized clinical trials: is blinding necessary? Control Clin Trials 1996;17(1):1 12.

13 Moher D, Cook DJ, Eastwood S, Olkin I, Rennie D, Stroup DF. Improving the quality of reports of meta-analyses of randomised controlled trials: the QUOROM statement. Lancet 1999;354:1896-900.

14 Freynhagen R, Strojek K, Griesing T, Whalen E, Balkenohl M. Efficacy of pregabalin in neuropathic pain evaluated in a 12-week, randomised, double-blind, multicentre, placebo-controlled trial of flexible- and fixed-dose regimens. Pain 2005;115:254-63.

15 Sindrup SH, Andersen G, Madsen C, Smith T, Brøsen K, Jesen TS. Tramadol relieves pain and allodynia in polyneuropathy: a randomized double-blind, controlled trial. Pain 1999;83:85-90

16 Sindrup SH, Madsen C, Brøsen K, Jesen TS. The effect of tramadol in painful polyneuropathy in relation to serum drug and metabolites levels. Clin Pharmacol Ther 1999;66:636-41.

17 Erdemoglu AK, Varlibas A. Effectiveness of oxcarbazepine in symptomatic treatment of painful diabetic neuropathy. Neurol India 2006;54:173-7.

18 Ertas M, Sagduyu A, Arac N, Uludag B, Ertekin C. Use of levodopa to relieve pain from painful symmetrical diabetic polyneuropathy. Pain 1998; $75: 257-9$.

19 Gorson KC, Schott C, Herman R, Ropper AH, Rand WM. Gabapentin in the treatment of painful diabetic neuropathy: a placebo controlled, double blind, crossover trial. J Neurol Neurosurg Psychiatry 1999;66:251-2.

20 Stracke H, Meyer UE, Schumacher HE, Federlin K. Mexiletine in the treatment of diabetic neuropathy. Diabetes Care 1992;15:1550-5.

21 Sindrup SH, Jensen TS. Efficacy of pharmacological treatments of neuropathic pain: an update and effect related to mechanism of drug action. Pain 1999;83:389-400.

22 Curtin F, Elbourne D, Altman DG. Meta-analysis combining parallel and cross-over clinical trials. III: The issue of carry-over. Stat Med 2002;21:2161-73.

23 Boulton AM, Knight G, Drury J, Ward JD. The prevalence of symptomatic diabetic neuropathy in an insulin treated population. Diabetes Care 1985;8:125-8.

24 Daousi C, MacFarlane IA, Woodward A, Nurmikko TJ, Bundred PE, Benbow SJ. Chronic painful peripheral neuropathy in an urban community: a controlled comparison of people with and without diabetes. Diabet Med 2004;21:976-82.

25 Galer BS, Gianas A, Jensen MP. Painful diabetic polyneuropathy: epidemiology, pain description, and quality of life. Diabetes Res Clin Pract 2000;47:123-8.

26 Otto M, Bak S, Bach FW, Jensen TS, Sindrup SH. Pain phenomena and possible mechanism in patients with painful polyneuropathy. Pain 2003;101:187-92.

Accepted: 13 April 2007 